\title{
The Long-Term Effectiveness of Internet-Based Interventions on Multiple Health Risk Behaviors: Systematic Review and Robust Variance Estimation Meta-analysis
}

Flora Tzelepis ${ }^{1,2,3}$, PhD; Aimee Mitchell ${ }^{1,2}$, BPsych (Hons); Louise Wilson ${ }^{1,2}$, BNutrDiet (Hons); Emma Byrnes ${ }^{1,3}$, BSocSc (Hons); Alexandra Haschek ${ }^{4,5}$, BPsych (Hons); Lucy Leigh ${ }^{3}, \mathrm{PhD}$; Christopher Oldmeadow ${ }^{3}, \mathrm{PhD}$

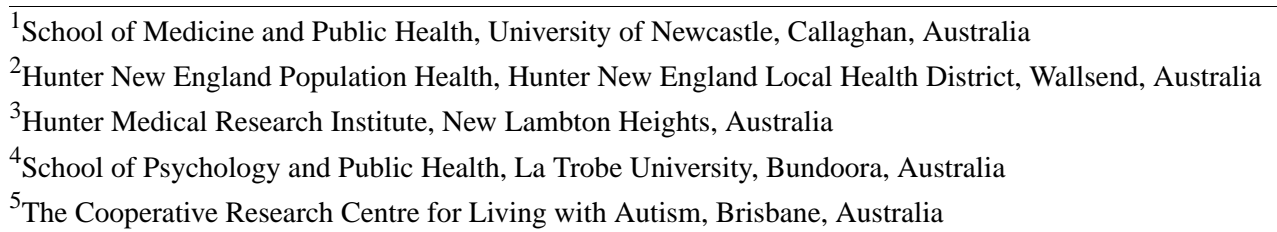

\section{Corresponding Author:}

Flora Tzelepis, $\mathrm{PhD}$

School of Medicine and Public Health

University of Newcastle

University Drive

Callaghan, 2308

Australia

Phone: 61249246275

Fax: 61249246490

Email: flora.tzelepis@newcastle.edu.au

\section{Abstract}

Background: Smoking tobacco, poor nutrition, risky alcohol use, and physical inactivity (SNAP) behaviors tend to cluster together. Health benefits may be maximized if interventions targeted multiple health risk behaviors together rather than addressing single behaviors. The internet has wide reach and is a sustainable mode for delivery of interventions for multiple health behaviors. However, no systematic reviews have examined the long-term effectiveness of internet-based interventions on any combination of or all SNAP behaviors in adults aged 18 years or older.

Objective: This systematic review examined, among adults (aged $\geq 18$ years), the effectiveness of internet-based interventions on SNAP behaviors collectively in the long term compared with a control condition.

Methods: The electronic databases Medline, PsycINFO, Embase, CINAHL, and Scopus were searched to retrieve studies describing the effectiveness of internet-based interventions on $\geq 2$ SNAP behaviors published by November 18, 2019. The reference lists of retrieved articles were also checked to identify eligible publications. The inclusion criteria were randomized controlled trials or cluster randomized controlled trials with adults examining an internet-based intervention measuring the effect on $\geq 2$ SNAP behaviors at least 6 months postrecruitment and published in English in a peer-reviewed journal. Two reviewers independently extracted data from included studies and assessed methodological quality using the Quality Assessment Tool for Quantitative Studies. A robust variance estimation meta-analysis was performed to examine the long-term effectiveness of internet-based interventions on all 4 SNAP risk behavior outcomes. All SNAP outcomes were coded so they were in the same direction, with higher scores equating to worse health risk behaviors.

Results: The inclusion criteria were met by 11 studies: 7 studies measured the effect of an internet-based intervention on nutrition and physical activity; 1 study measured the effect on smoking, nutrition, and physical activity; and 3 studies measured the effect on all SNAP behaviors. Compared with the control group, internet-based interventions achieved an overall significant improvement across all SNAP behaviors in the long term (standardized mean difference -0.12 [improvement as higher scores = worse health risk outcomes], $95 \% \mathrm{CI}-0.19$ to $-0.05 ; \mathrm{I}^{2}=1.5 \%, P=.01$ ). The global methodological quality rating was "moderate" for 1 study, while the remaining 10 studies were rated as "weak." 
Conclusions: Internet-based interventions were found to produce an overall significant improvement across all SNAP behaviors collectively in the long term. Internet-based interventions targeting multiple SNAP behaviors have the potential to maximize long-term improvements to preventive health outcomes.

(J Med Internet Res 2021;23(12):e23513) doi: 10.2196/23513

\section{KEYWORDS}

internet; multiple health behaviors; tobacco; nutrition; alcohol; physical activity

\section{Introduction}

Smoking tobacco, poor nutrition, risky alcohol use, and physical inactivity (SNAP) are modifiable risk factors for chronic diseases such as heart disease, stroke, cancer, and diabetes [1]. Individuals who engage in all 4 SNAP behaviors, compared with 0 , have an increased risk of mortality, equivalent to 14 years of aging [2]. Evidence has shown that SNAP behaviors tend to cluster together [3-5], suggesting a holistic approach for interventions to modify multiple health behaviors collectively rather than single behaviors individually may be beneficial. Multiple health behavior interventions target 2 or more health behaviors either sequentially or simultaneously [6]. Advantages of improving multiple health behaviors include maximizing health benefits [7], greater reduction in medical costs [8], and successfully modifying one behavior may increase confidence or motivation to change other health behaviors $[7,9]$.

The internet is accessible globally and is a sustainable mode for the delivery of interventions for multiple health behaviors [10]. There are more than 4 billion internet users worldwide [10]; therefore, internet-based interventions have the potential to reach large numbers of people. Other advantages of internet-based interventions include that users can access information any time $[11,12]$ as well as a low-cost modality for information delivery [11,12] and allowing for privacy, confidentiality [11], and long-term use [12,13]. Internet-based interventions may be interactive [11-13] and incorporate behavior change techniques such as individually tailored information [11,13], goal setting [12-14], self-monitoring [12-14], personalized and normative feedback $[11,12,14]$, and progress tracking $[12,13]$. Internet-based interventions may also reduce health inequalities by improving access to services, for example among individuals who live in rural and remote areas or have significant mobility issues $[13,15]$.

Existing systematic reviews have examined the effectiveness of behavioral interventions on multiple health risk behaviors $[16,17]$. A systematic review of nonpharmacologic interventions on multiple health risk behaviors found modest improvements in fruit and vegetable intake, physical activity, reduced fat intake, and reduced smoking [16]. Furthermore, another systematic review examining the efficacy of apps in children, adolescents, and adults reported that $41 \%$ of multiple health behavior interventions showed significant between-group improvements in behaviors [17]. However, only 2 systematic reviews have specifically examined the effectiveness of internet-based interventions on 2 or more SNAP behaviors in adult populations $[18,19]$. The review by Norman et al [18] focused on interventions for nutrition and physical activity but not tobacco use and alcohol intake. Of the 17 studies targeting multiple behaviors, 6 studies favored an internet-based intervention for increasing physical activity, and 6 studies favored an internet-based intervention for changing nutrition behaviors [18]. However, this systematic review was not restricted to adult populations, and findings from children and adolescents were included in the synthesis of findings [18]. Furthermore, short-term follow-up assessments were contained within this systematic review, and many studies did not report the effect of the internet-based intervention on nutrition and physical activity in the long term [18]. In the second systematic review, Oosterveen and colleagues [19] examined the effectiveness of internet-based interventions on combinations of all SNAP behaviors but included young adults aged 18 years to 35 years only. This systematic review identified only 2 studies with young adults targeting nutrition and physical activity behaviors that included a long-term follow-up (ie, 6 months or longer) [19]. To our knowledge, there is no systematic review that has examined the long-term effectiveness of internet-based interventions on any combination of or all SNAP behaviors in adults aged 18 years or older. Further critical review of the evidence is therefore needed to understand whether internet-based interventions are effective in improving multiple SNAP behaviors in the long term.

This systematic review aimed to examine the effectiveness of internet-based interventions on multiple SNAP health risk behaviors in the long term compared with a control condition.

\section{Methods}

\section{Search Strategy and Selection Criteria}

The electronic databases Medline, PsycINFO, Embase, CINAHL, and Scopus were searched to retrieve studies describing the effectiveness of internet-based interventions on 2 or more SNAP behaviors published by November 18, 2019. The following combinations of keywords were used: (multiple health behavio* or multiple behavio* or multiple risk* or multiple health* or smok* or tobacco or alcohol or diet* or nutrition or exercise or physical activity or fruit* or vegetable*) AND (internet or web* or online or on-line) AND (trial* or $\mathrm{RCT}^{*}$ or random*). The reference lists of retrieved articles were also checked to identify any additional eligible publications.

The inclusion criteria were studies (1) that reported randomized controlled trials (RCTs) or cluster RCTs of internet-based interventions for $\geq 2$ SNAP behaviors as either the sole intervention or an adjunct to written materials, (2) with adults aged 18 years or older, (3) that reported outcomes for $\geq 2$ SNAP behaviors at least 6 months postrecruitment, (4) that had a no-intervention control group or the control group received information either in hard copy or information unrelated to 
SNAP via a website, and (5) in the English language in a peer-reviewed journal.

Publications were excluded if (1) they did not report the outcomes of an RCT or cluster RCT (eg, systematic reviews, commentaries); (2) they examined only 1 SNAP health behavior;

(3) they included special populations only such as people with chronic conditions (eg, cancer, diabetes) or pregnant women (this criterion was chosen because people with chronic conditions may differ in their motivation and capacity to change behaviors compared with those without chronic conditions and is consistent with the criterion set in another systematic review that examined multiple health risk behaviors [16]); (4) were conducted with people under 18 years of age; (5) outcome measures were not related to SNAP (eg, blood pressure); (6) the internet-based intervention was part of a multicomponent approach that included other modes of support (eg, face-to-face, telephone); (7) there was no control arm, and instead, comparisons were made with other interventions (eg, face-to-face support); and (8) SNAP outcomes were measured before 6 months postrecruitment.

\section{Selection of Eligible Studies}

This systematic review was conducted in accordance with PRISMA (Preferred Reporting Items for Systematic Reviews and Meta-Analyses) guidelines [20]. All records identified in each electronic database were imported into Endnote, and duplicates were removed. Titles, abstracts, and full texts of each reference were independently screened in duplicate by 2 reviewers (LW and FT or AM or EB) to determine if eligibility criteria were met. Full-text articles were retrieved when eligibility could not be determined from the title and abstract screening.

\section{Study and Sample Characteristics}

Data were independently extracted from the included studies by 2 authors (AM and AH or LW). A third author (FT) resolved any inconsistencies in data extraction. The study and sample characteristics extracted from eligible publications included authors and year of publication, country, years that data were collected, setting, sample characteristics (eg, mean age, gender, education, employment status), recruitment method, eligibility criteria, treatment conditions (relevant arms only; ie, internet-based intervention and control arms), internet-based intervention received (eg, duration, number of modules), retention rate at follow-up, SNAP measures, SNAP outcomes at 6 months of follow-up or later, and costs.

The outcomes extracted for each health behavior were any measure of (1) tobacco smoking (eg, current tobacco smoking, point prevalence abstinence, or prolonged abstinence), (2) nutrition (eg, number of daily serves of fruit and vegetables, dietary score), (3) alcohol consumption (eg, number of alcoholic drinks per day), and (4) physical activity (eg, moderate to vigorous physical activity, metabolic equivalent of task [MET] minutes per week).

\section{Methodological Quality Assessment}

The Quality Assessment Tool for Quantitative Studies developed by the Effective Public Health Practice Project was used to assess methodological quality [21]. This tool was chosen because it has demonstrated content validity, construct validity, and test-retest reliability [22] and has been shown to have higher interrater reliability than the Cochrane Collaboration Risk of Bias Tool [23]. The Quality Assessment Tool for Quantitative Studies allows randomized trials to be rated on 6 components: (1) selection bias, (2) study design, (3) confounders, (4) blinding, (5) data collection methods, and (6) withdrawals and dropouts. Each study was rated as "strong," "moderate," or "weak" for each component. An overall global rating was then assigned to each study, with studies classified as "strong" (no weak ratings), "moderate" (1 weak rating), or "weak" (2 or more weak ratings). The Quality Assessment Tool for Quantitative Studies Dictionary was used to make judgments about each of the 6 components [24].

The methodological quality of included studies was rated by 2 authors (FT and AM). Any discrepancies were discussed between these authors until consensus was reached. When rating the data collection methods, the measures for "all" SNAP outcomes needed to be shown to be valid and reliable for the data collection methods to be rated as strong. For instance, if smoking cessation was measured via biochemical validation and physical activity assessed via pedometers, the data collection methods were rated as strong. However, if smoking cessation was measured via a self-reported measure with no information about its psychometric properties and pedometers were used to assess physical activity, the data collection methods were rated as weak because "all" SNAP measures were not shown to be reliable and valid.

\section{Robust Variance Estimation Meta-analysis}

A robust variance estimation meta-analysis was performed using the R package robumeta. All SNAP behaviors were coded so they were in the same direction, with higher scores equating to worse health risk outcomes. Where a study measured the outcome at multiple time points (eg, 6 months and 12 months), data from the longer-term follow-up was included in the meta-analysis. The SNAP outcomes from each study were converted into Cohen d (standardized mean differences [SMDs]) and the corresponding variance [25]. Robust variance estimation meta-analysis was then performed on the SMDs (and variances), using the $\mathrm{R}$ package robumeta. A common within-study correlation (rho) of 0.8 was assumed, and sensitivity analyses were performed to determine the sensitivity of the results to this assumption (by looking at the results across various rho equal to $0,0.2,0.4,0.6$, or 1.0$)$. Heterogeneity was measured using the $\mathrm{I}^{2}$ statistic [26].

\section{Results}

\section{Search Results}

The PRISMA flow diagram outlining the study selection process is presented in Figure 1. A total of 34,673 records were identified from the electronic database searches. After the removal of duplicates, 16,420 records had their title and/or abstract screened, and 16,341 did not meet the inclusion criteria. The full texts of the remaining 79 articles were retrieved for further review, and 68 articles were excluded for the following 
reasons: multicomponent intervention $(n=29)$, not an RCT $(n=19)$, did not measure 2 or more SNAP behaviors $(n=7)$, less than 6 months of follow-up $(n=6)$, did not include a no-intervention or self-help control group $(n=4)$, not an internet-based intervention $(\mathrm{n}=2)$, and population with chronic disease $(n=1)$. The inclusion criteria for this review were met by 11 studies.

Figure 1. PRISMA (Preferred Reporting Items for Systematic Reviews and Meta-Analyses) diagram of the screening and selection process. RCT: randomized controlled trial.

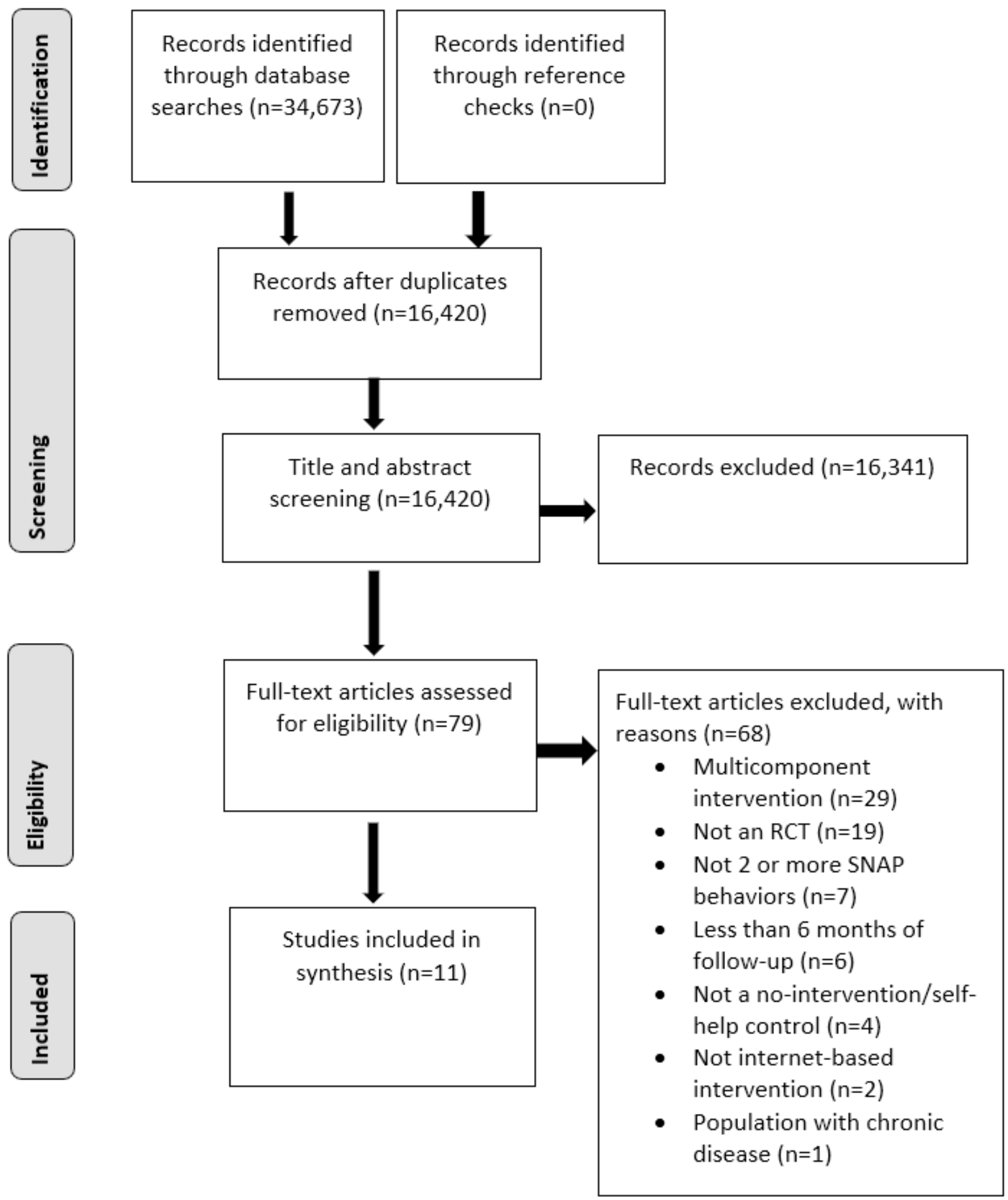




\section{Study Characteristics of Internet-Based Interventions for Multiple Health Risk Behaviors}

\section{Studies That Examined Nutrition and Physical Activity}

As shown in Multimedia Appendix 1, the effectiveness of an internet-based intervention on nutrition and physical activity was examined by 7 studies [27-33]; 5 studies were conducted in the United States [27,29,30,32,33], and 1 study each was conducted in the United Kingdom [31] and Australia [28]. Recruitment occurred from the community in 3 studies [28,32,33], from health care settings in 2 studies [27,31], and from universities in 2 studies [29,30]. In 6 studies, participants were recruited via various advertisements (eg, website, emails, newspaper, flyers, posters, radio) [27,28,30-33], while 2 studies used sign-up tables at universities [29,30]. The sample size ranged from 121 [27] to 1071 [33]. Only men were included in 2 studies [28,32], and only women were included in 1 study [27]. The percentage of women ranged from 56.3\% (268/476) to $77 \%(171 / 221)$ in the remaining studies $[29-31,33]$.

The interventions included web-based learning activities, modules, or tutorials [27,30,32,33]; self-monitoring [28,32]; educational materials [28,29,31]; social support [28]; tailored information [27,30-33]; feedback [32]; and goal setting [32,34]. The duration of engagement with the internet-based interventions ranged from 2 sessions [29] to a 12-month trial period [31]. Nutrition and physical activity were measured via self-reported measures in 6 studies [27-32], while 1 study used self-reported measures for nutrition and pedometers for physical activity [33]. Nutrition and physical activity were assessed at 6 months in 4 studies (range of retention of $291 / 441,66.0 \%$ to 105/121, 86.8\% [27,29,31,32]), 7 months in 1 study (retention: 950/1071, 88.7\% [33]), 9 months in 1 study (retention: 148/317, $46.7 \%$ [28]), 12 months in 2 studies (retention: 131/221, 59.3\% and $309 / 441,70.1 \%$ [31,32]), 15 months in 1 study (retention: $1126 / 1689,66.7 \%$ [30]), and 16 months in 1 study (retention: 935/1071, 87.3\% [33]).

\section{Studies That Examined Smoking, Nutrition, and Physical Activity}

Multimedia Appendix 2 describes the study characteristics of the US study examining the effectiveness of an internet-based intervention on smoking, nutrition, and physical activity [34]. This study recruited 423 university staff (female: 347/423, 82\%; mean age 51 years) via announcements on staff listservs, targeted emails, recruitment tables at events, and flyers [34]. The RealAge internet program generated individual risk profiles and allowed users to select behaviors to change and create plans to meet behavioral goals [34]. Self-reported measures assessed smoking cessation, nutrition, and physical activity at 6-month (retention: 360/423, 85.1\%) and 12-month (retention: 367/423, $86.8 \%$ ) follow-ups [34].

\section{Studies That Examined Smoking, Nutrition, Alcohol, and Physical Activity}

As outlined in Multimedia Appendix 3, the effectiveness of internet-based interventions on smoking, nutrition, alcohol, and physical activity was assessed by 3 studies [35-37]. All studies were conducted in the United Kingdom [35-37]; 2 studies were undertaken in the university setting [35,36], and 1 study was conducted in the community [37]. In 2 studies, incoming undergraduate students were recruited via an email invitation $[35,36]$, while online and print advertisements were used to recruit participants in the community study [37]. Across the 3 studies, the sample size ranged from 100 [37] to 2621 [35]. Most participants were women in all the studies (range: $1447 / 2614,55.4 \%$ to $82 / 100,82 \%$ [35-37]), and the mean age ranged from 18.8 years [35] to 39 years [37]. The U@Uni [36] and U@Uni:LifeGuide [35] internet-based interventions included a profile page containing self-affirmation manipulation, theory-based messages for each SNAP behavior, and a planner to form implementation intentions. The HealthyValues Healthy Eating program targeted motivation, volition, and maintenance and included weekly tasks for 24 weeks [37]. All studies measured SNAP outcomes via self-reported measures at a 6-month follow-up [35-37]. The retention rates at 6 months were $41.2 \%$ (1079/2621) [35], 63.2\% (913/1445) [36], and 95\% $(95 / 100)$ [37], respectively.

\section{Long-Term Effectiveness of Internet-Based Interventions Across SNAP Risk Behaviors}

The robust variance estimation meta-analysis found that, compared with the control group, internet-based interventions achieved an overall significant improvement across all SNAP behaviors in the long-term (SMD - 0.12 [improvement as higher scores $=$ worse health risk outcomes], $95 \% \mathrm{CI}-0.19$ to -0.05 ; $\left.\mathrm{I}^{2}=1.5 \%, P=.01\right)[27,29,30,32,34-37]$. Heterogeneity was low $\left(\mathrm{I}^{2}=1.5 \%\right)$, and the tau-square (the extent of variation due to between-study variance) was low, at $<0.001$. The sensitivity analysis showed that the model results did not vary greatly across different values of within-study correlation (rho).

\section{Methodological Quality Assessment}

Table 1 presents the methodological quality ratings for the 6 components and the global rating as assessed via the Quality Assessment Tool for Quantitative Studies [21]. In terms of selection bias, all studies were rated "weak," as 9 of these studies recruited volunteers who responded to advertisements or sign-up tables [27-34,37], and 2 studies sent emails to all incoming undergraduate students but recruited less than half of those approached [35,36]. All included studies were RCTs or cluster RCTs and were rated as "strong" in terms of study design [27-37]. With regards to confounders, 8 studies were rated as "strong" because there were no between-group differences at baseline [31,32,34,35,37] or adjustments for baseline characteristics were made during analysis $[27,29,36]$, while 1 study was rated as "moderate," as stratification attempted to balance baseline characteristics across groups [33], and 2 studies were rated as "weak," as no adjustments were made during analysis for baseline characteristics that differed between the groups $[28,30]$. For blinding, 9 studies were rated as "weak" because the assessors and participants were not blinded $[28,31,34]$ or there was no information about blinding $[27,29,30,33,35,36]$, while 2 studies were rated as "moderate" because only the assessors were blinded to the condition [32,37]. For data collection methods, 8 studies were rated as "weak," as all relevant SNAP measures were not shown to be valid or reliable (either via the use of an objective measure or demonstration of acceptable psychometric properties of a 
self-reported measure) [27,30,31,33-37], while 3 studies were classified as "strong," as all SNAP measures used were valid and reliable [28,29,32]. In relation to withdrawals and dropouts, 4 studies were rated as "strong," with retention rates $\geq 80 \%$ (105/121; 935/1071; 367/423; 95/100) [27,33,34,37]; 4 studies were rated as "moderate," with retention rates between $60 \%$ and 79\% (422/606; 1126/1689; 309/441; 913/1445) [29,30,32,36]; and 3 studies were rated as "weak," with retention rates $<60 \%(148 / 317 ; 131 / 221 ; 1079 / 2621)[28,31,35]$. In terms of the global rating, 1 study was rated as "moderate" [32], and the remaining 10 studies were rated as "weak" [27-31,33-37].

Table 1. Methodological quality assessment of included studies.

\begin{tabular}{|c|c|c|c|c|c|c|c|}
\hline Study & $\begin{array}{l}\text { Selection } \\
\text { bias }\end{array}$ & Study design & Confounders & Blinding & $\begin{array}{l}\text { Data collection } \\
\text { method }\end{array}$ & $\begin{array}{l}\text { Withdrawals and } \\
\text { dropouts }\end{array}$ & Global rating \\
\hline \multicolumn{8}{|c|}{ Nutrition and physical activity studies } \\
\hline $\begin{array}{l}\text { Drieling et al } \\
{[27]}\end{array}$ & Weak & Strong & Strong & Weak & Weak & Strong & Weak \\
\hline $\begin{array}{l}\text { Duncan et al } \\
{[28]}\end{array}$ & Weak & Strong & Weak & Weak & Strong & Weak & Weak \\
\hline $\begin{array}{l}\text { Franko et al } \\
\text { [29] }\end{array}$ & Weak & Strong & Strong & Weak & Strong & Moderate & Weak \\
\hline $\begin{array}{l}\text { Greene et al } \\
{[30]}\end{array}$ & Weak & Strong & Weak & Weak & Weak & Moderate & Weak \\
\hline $\begin{array}{l}\text { McConnon et al } \\
\text { [31] }\end{array}$ & Weak & Strong & Strong & Weak & Weak & Weak & Weak \\
\hline $\begin{array}{l}\text { Patrick et al } \\
{[32]}\end{array}$ & Weak & Strong & Strong & Moderate & Strong & Moderate & Moderate \\
\hline $\begin{array}{l}\text { Winett et al } \\
\text { [33] }\end{array}$ & Weak & Strong & Moderate & Weak & Weak & Strong & Weak \\
\hline \multicolumn{8}{|c|}{ Smoking, nutrition, and physical activity study } \\
\hline $\begin{array}{l}\text { Hughes et al } \\
{[34]}\end{array}$ & Weak & Strong & Strong & Weak & Weak & Strong & Weak \\
\hline \multicolumn{8}{|c|}{ Smoking, nutrition, alcohol, and physical activity studies } \\
\hline $\begin{array}{l}\text { Cameron et al } \\
{[35]}\end{array}$ & Weak & Strong & Strong & Weak & Weak & Weak & Weak \\
\hline Epton et al [36] & Weak & Strong & Strong & Weak & Weak & Moderate & Weak \\
\hline
\end{tabular}

\section{Discussion}

\section{Principal Findings}

This is the first systematic review to examine the long-term effectiveness of internet-based interventions on SNAP behaviors collectively in adults aged 18 years or older. This systematic review focused on internet-based interventions to increase the homogeneity of included studies. This is similar to other systematic reviews that have focused on a specific digital technology [38,39]. More broadly, however, digital technologies can also include text messaging, email, mobile applications, video conferencing [40], and just-in-time feedback interventions [41]. The studies included in this systematic review most commonly examined effectiveness on 2 SNAP behaviors, namely nutrition and physical activity [27-33]. Only 3 studies examined the effectiveness of internet-based interventions on all 4 SNAP behaviors [35-37], whereas 1 study measured the effect on 3 behaviors (ie, tobacco smoking, nutrition, physical activity) [34].
The robust variance estimation meta-analysis findings reported that internet-based interventions achieved an overall significant improvement across all SNAP behaviors in the long term. This suggests that internet-based interventions that adopt a holistic approach to behavior change by addressing multiple SNAP behaviors improve these behaviors collectively and consequently may lead to better health outcomes and reduced health care costs. Given no previous systematic reviews have examined the long-term effectiveness of internet-based interventions on multiple SNAP behaviors nor provided an overall effect size across all SNAP behaviors, we cannot compare our findings to previous reviews. To advance the field, further research is needed on the long-term effectiveness of internet-based interventions on multiple SNAP behaviors.

The studies in this systematic review recruited participants from a variety of settings, including universities [29,30,34-36], the community [28,32,33,37], and health care [27,31]. Among the 5 studies conducted in universities, only 1 study reported a significant treatment effect on both nutrition and physical activity [30], while another study found the intervention reduced 
current smoking but had no effect on nutrition, alcohol, and physical activity [36]. Of 4 studies conducted in the community, 2 studies reported a significant treatment effect of the internet-based intervention on nutrition and some physical activity outcomes [32] or on some nutrition outcomes but not physical activity [33]. The trials that recruited participants from health care settings found no significant differences between the internet-based intervention and the control condition [27,31]. Additional research is needed across a variety of settings to expand the evidence base examining the long-term effectiveness of internet-based interventions on combinations of 2 or more SNAP behaviors.

In terms of methodological quality, 10 of 11 studies had a global rating of "weak" [27-31,33-37], with only 1 study rated as "moderate" [32]. Improvements to methodological rigor are particularly needed for selection bias, blinding, and data collection methods. Selection bias could be reduced by using recruitment methods that aim to enroll a representative sample (eg, random selection of potential participants) while data collection methods could be improved via objective measures (eg, pedometers for physical activity, biochemical validation for smoking cessation) for all SNAP behaviors assessed. Given the nature of behavioral interventions, blinding is often difficult; however, future studies should attempt to blind assessors and participants where possible.

\section{Limitations}

This systematic review had some limitations. First, although we were able to pool the studies to undertake a robust variance estimation meta-analysis to examine the long-term effectiveness of internet-based interventions across all SNAP behaviors, additional analyses examining potential moderators (eg, country) were not possible due to the relatively small number of studies in this systematic review. Second, the methodological quality assessments were based on the information contained in the articles, and missing details from these articles may have had an impact on the ratings. Finally, all the studies were conducted in high-income countries, which may limit the generalizability of this systematic review's findings to low- and middle-income countries. In addition to expanding the research in the settings and populations included in this review, future research should assess the long-term effectiveness of internet-based interventions on multiple SNAP behaviors in additional populations (eg, culturally and linguistically diverse groups, Indigenous), settings (eg, vocational education settings, rural and remote locations), and countries (eg, low- and middle-income) to strengthen the evidence base and improve the generalizability of the findings.

\section{Conclusions}

Internet-based interventions were found to produce an overall significant improvement across all SNAP behaviors in the long term. Given the promising findings on the long-term effectiveness of internet-based interventions across all SNAP behaviors collectively, such interventions may maximize improvements to health and prevent chronic diseases.

\section{Acknowledgments}

The School of Medicine and Public Health at the University of Newcastle, Hunter New England Population Health, and the Hunter Medical Research Institute provided infrastructure support. FT was supported by a Heart Foundation Postdoctoral Fellowship (100128), followed by a National Health and Medical Research Council (NHMRC) Career Development Fellowship (APP1143269). The sponsors had no role in study design; in the collection, analyses, and interpretation of data; in the writing of the manuscript; and in the decision to submit the article for publication.

\section{Conflicts of Interest}

None declared.

\section{Multimedia Appendix 1}

Characteristics of studies examining the effectiveness of an internet-based intervention on nutrition and physical activity. [DOCX File, 34 KB-Multimedia Appendix 1]

\section{Multimedia Appendix 2}

Characteristics of studies examining the effectiveness of an internet-based intervention on smoking, nutrition, and physical activity.

[DOCX File, 22 KB-Multimedia Appendix 2]

\section{Multimedia Appendix 3}

Characteristics of studies examining the effectiveness of an internet-based intervention on smoking, nutrition, alcohol, physical activity (SNAP).

[DOCX File, 26 KB-Multimedia Appendix 3]

\section{References}


1. GBD 2015 Risk Factors Collaborators. Global, regional, and national comparative risk assessment of 79 behavioural, environmental and occupational, and metabolic risks or clusters of risks, 1990-2015: a systematic analysis for the Global Burden of Disease Study 2015. Lancet 2016 Oct 08;388(10053):1659-1724 [FREE Full text] [doi: 10.1016/S0140-6736(16)31679-8] [Medline: 27733284]

2. Khaw K, Wareham N, Bingham S, Welch A, Luben R, Day N. Combined impact of health behaviours and mortality in men and women: the EPIC-Norfolk prospective population study. PLoS Med 2008 Jan 08;5(1):e12 [FREE Full text] [doi: 10.1371/journal.pmed.0050012] [Medline: 18184033]

3. Lippke S, Nigg CR, Maddock JE. Health-promoting and health-risk behaviors: theory-driven analyses of multiple health behavior change in three international samples. Int J Behav Med 2012 Mar 14;19(1):1-13 [FREE Full text] [doi: 10.1007/s12529-010-9135-4] [Medline: 21234735]

4. Kang J, Ciecierski CC, Malin EL, Carroll AJ, Gidea M, Craft LL, et al. A latent class analysis of cancer risk behaviors among U.S. college students. Prev Med 2014 Jul;64:121-125 [FREE Full text] [doi: 10.1016/j.ypmed.2014.03.023] [Medline: 24704131]

5. Paul C, Tzelepis F, Bisquera A, Noble N, Wiggers J. Just how high-risk are ongoing smokers? Exploring clusters of health risk behaviours among current and ex-smokers. Prev Med 2016 Dec;93:70-75. [doi: 10.1016/j.ypmed.2016.09.021] [Medline: 27670372]

6. James E, Freund M, Booth A, Duncan MJ, Johnson N, Short CE, et al. Comparative efficacy of simultaneous versus sequential multiple health behavior change interventions among adults: A systematic review of randomised trials. Prev Med 2016 Aug;89:211-223. [doi: 10.1016/j.ypmed.2016.06.012] [Medline: 27311332]

7. Prochaska JJ, Spring B, Nigg CR. Multiple health behavior change research: an introduction and overview. Prev Med 2008 Mar;46(3):181-188 [FREE Full text] [doi: 10.1016/j.ypmed.2008.02.001] [Medline: 18319098]

8. Edington DW, Yen LT, Witting P. The financial impact of changes in personal health practices. J Occup Environ Med 1997 Nov;39(11):1037-1046. [doi: 10.1097/00043764-199711000-00004] [Medline: 9383715]

9. Johnson SS, Paiva AL, Cummins CO, Johnson JL, Dyment SJ, Wright JA, et al. Transtheoretical model-based multiple behavior intervention for weight management: effectiveness on a population basis. Prev Med 2008 Mar;46(3):238-246 [FREE Full text] [doi: 10.1016/j.ypmed.2007.09.010] [Medline: 18055007]

10. Bommelaer de Leusse C, Gahnberg C. The Global Internet Report: Consolidation in the Internet Economy. Internet Society. 2019. URL: https://future.internetsociety.org/2019/wp-content/uploads/sites/2/2019/04/

InternetSociety-GlobalInternetReport-ConsolidationintheInternetEconomy.pdf [accessed 2020-04-30]

11. Evers KE, Prochaska JM, Prochaska JO, Driskell M, Cummins CO, Velicer WF. Strengths and weaknesses of health behavior change programs on the internet. J Health Psychol 2003 Jan 01;8(1):63-70. [doi: 10.1177/1359105303008001435] [Medline: 22113901]

12. Rogers MA, Lemmen K, Kramer R, Mann J, Chopra V. Internet-delivered health interventions that work: systematic review of meta-analyses and evaluation of website availability. J Med Internet Res 2017 Mar 24;19(3):e90 [FREE Full text] [doi: 10.2196/jmir.7111] [Medline: 28341617]

13. Lustria MLA, Noar SM, Cortese J, Van Stee SK, Glueckauf RL, Lee J. A meta-analysis of web-delivered tailored health behavior change interventions. J Health Commun 2013 Sep;18(9):1039-1069. [doi: 10.1080/10810730.2013.768727] [Medline: 23750972]

14. Webb TL, Joseph J, Yardley L, Michie S. Using the internet to promote health behavior change: a systematic review and meta-analysis of the impact of theoretical basis, use of behavior change techniques, and mode of delivery on efficacy. J Med Internet Res 2010 Feb 17;12(1):e4 [FREE Full text] [doi: 10.2196/jmir.1376] [Medline: 20164043]

15. Murray E. Web-based interventions for behavior change and self-management: potential, pitfalls, and progress. Med 20 2012 Aug 14;1(2):e3 [FREE Full text] [doi: 10.2196/med20.1741] [Medline: 25075231]

16. Meader N, King K, Wright K, Graham HM, Petticrew M, Power C, et al. Multiple risk behavior interventions: meta-analyses of RCTs. Am J Prev Med 2017 Jul;53(1):e19-e30 [FREE Full text] [doi: 10.1016/j.amepre.2017.01.032] [Medline: 28258777]

17. Schoeppe S, Alley S, Van Lippevelde W, Bray NA, Williams SL, Duncan MJ, et al. Efficacy of interventions that use apps to improve diet, physical activity and sedentary behaviour: a systematic review. Int J Behav Nutr Phys Act 2016 Dec 07;13(1):127 [FREE Full text] [doi: 10.1186/s12966-016-0454-y] [Medline: 27927218]

18. Norman GJ, Zabinski MF, Adams MA, Rosenberg DE, Yaroch AL, Atienza AA. A review of eHealth interventions for physical activity and dietary behavior change. Am J Prev Med 2007 Oct;33(4):336-345 [FREE Full text] [doi: 10.1016/j.amepre.2007.05.007] [Medline: 17888860]

19. Oosterveen E, Tzelepis F, Ashton L, Hutchesson MJ. A systematic review of eHealth behavioral interventions targeting smoking, nutrition, alcohol, physical activity and/or obesity for young adults. Prev Med 2017 Jun;99:197-206. [doi: 10.1016/j.ypmed.2017.01.009] [Medline: 28130046]

20. Moher D, Liberati A, Tetzlaff J, Altman DG, PRISMA Group. Preferred reporting items for systematic reviews and meta-analyses: the PRISMA statement. BMJ 2009 Jul 21;339(jul21 1):b2535-b2535 [FREE Full text] [doi: 10.1136/bmj.b2535] [Medline: 19622551]

21. Quality Assessment Tool for Quantitative Studies. Effective Public Health Practice Project (EPHPP). URL: https://merst. ca/wp-content/uploads/2018/02/quality-assessment-tool 2010.pdf [accessed 2020-02-03] 
22. Thomas B, Ciliska D, Dobbins M, Micucci S. A process for systematically reviewing the literature: providing the research evidence for public health nursing interventions. Worldviews on Evidence-Based Nursing 2004 Jun 23;1(3):176-184. [doi: 10.1111/j.1524-475x.2004.04006.x ]

23. Armijo-Olivo S, Stiles C, Hagen N, Biondo P, Cummings G. Assessment of study quality for systematic reviews: a comparison of the Cochrane Collaboration Risk of Bias Tool and the Effective Public Health Practice Project Quality Assessment Tool: methodological research. J Eval Clin Pract 2012 Feb;18(1):12-18. [doi: 10.1111/j.1365-2753.2010.01516.x] [Medline: 20698919]

24. Quality Asessment Tool for Quantitative Studies Dictionary. Effective Public Health Practice Project (EPHPP). URL: https://merst.ca/wp-content/uploads/2018/02/qualilty-assessment-dictionary 2017.pdf [accessed 2020-02-03]

25. Borenstein MH, Hedges LV, Higgins JPT, Rothstein HR. Converting among effect sizes. In: Borenstein MH, Hedges LV, Higgins JPT, Rothstein HR, editors. Introduction to meta-analysis. Hoboken, NJ: John Wiley \& Sons; 2009.

26. Higgins JT, Thomas J, Chandler J, Cumpston M, Li T, Page M, et al. Cochrane Handbook for Systematic Reviews of Interventions version 6.2. Cochrane. 2021. URL: https://training.cochrane.org/handbook [accessed 2021-04-30]

27. Drieling RL, Ma J, Thiyagarajan S, Stafford RS. An Internet-based osteoporotic fracture risk program: effect on knowledge, attitudes, and behaviors. J Womens Health (Larchmt) 2011 Dec;20(12):1895-1907. [doi: 10.1089/jwh.2010.2515] [Medline: 21970565]

28. Duncan M, Vandelanotte C, Kolt GS, Rosenkranz RR, Caperchione CM, George ES, et al. Effectiveness of a web- and mobile phone-based intervention to promote physical activity and healthy eating in middle-aged males: randomized controlled trial of the ManUp study. J Med Internet Res 2014 Jun 12;16(6):e136 [FREE Full text] [doi: 10.2196/jmir.3107] [Medline: 24927299]

29. Franko DL, Cousineau TM, Trant M, Green TC, Rancourt D, Thompson D, et al. Motivation, self-efficacy, physical activity and nutrition in college students: randomized controlled trial of an internet-based education program. Prev Med 2008 Oct;47(4):369-377 [FREE Full text] [doi: 10.1016/j.ypmed.2008.06.013] [Medline: 18639581]

30. Greene GW, White AA, Hoerr SL, Lohse B, Schembre SM, Riebe D, et al. Impact of an online healthful eating and physical activity program for college students. Am J Health Promot 2012 Nov 01;27(2):e47-e58. [doi: 10.4278/ajhp.110606-quan-239]

31. McConnon A, Kirk SF, Cockroft JE, Harvey EL, Greenwood DC, Thomas JD, et al. The internet for weight control in an obese sample: results of a randomised controlled trial. BMC Health Serv Res 2007 Dec 19;7(1):206 [FREE Full text] [doi: 10.1186/1472-6963-7-206] [Medline: 18093289]

32. Patrick K, Calfas KJ, Norman GJ, Rosenberg D, Zabinski MF, Sallis JF, et al. Outcomes of a 12-month web-based intervention for overweight and obese men. Ann Behav Med 2011 Dec 6;42(3):391-401. [doi: 10.1007/s12160-011-9296-7] [Medline: 21822750]

33. Winett RA, Anderson ES, Wojcik JR, Winett SG, Bowden T. Guide to health: Nutrition and physical activity outcomes of a group-randomized trial of an internet-based intervention in churches. Ann. Behav. Med 2007 Sep;33(3):251-261. [doi: 10.1007/bf02879907]

34. Hughes SL, Seymour RB, Campbell RT, Shaw JW, Fabiyi C, Sokas R. Comparison of two health-promotion programs for older workers. Am J Public Health 2011 May;101(5):883-890. [doi: 10.2105/ajph.2010.300082]

35. Cameron D, Epton T, Norman P, Sheeran P, Harris PR, Webb TL, et al. A theory-based online health behaviour intervention for new university students (U@Uni:LifeGuide): results from a repeat randomized controlled trial. Trials 2015 Dec 07;16(1):555 [FREE Full text] [doi: 10.1186/s13063-015-1092-4] [Medline: 26643917]

36. Epton T, Norman P, Dadzie A, Harris PR, Webb TL, Sheeran P, et al. A theory-based online health behaviour intervention for new university students (U@Uni): results from a randomised controlled trial. BMC Public Health 2014 Jun 05;14(1):563 [FREE Full text] [doi: 10.1186/1471-2458-14-563] [Medline: 24903620]

37. Tapper K, Jiga-Boy G, Maio GR, Haddock G, Lewis M. Development and preliminary evaluation of an internet-based healthy eating program: randomized controlled trial. J Med Internet Res 2014 Oct 10;16(10):e231 [FREE Full text] [doi: 10.2196/jmir.3534] [Medline: 25305376]

38. Taylor G, Dalili M, Semwal M, Civljak M, Sheikh A, Car J. Internet-based interventions for smoking cessation. Cochrane Database Syst Rev 2017 Sep 04;9:CD007078 [FREE Full text] [doi: 10.1002/14651858.CD007078.pub5] [Medline: 28869775]

39. Tzelepis F, Paul C, Williams C, Gilligan C, Regan T, Daly J, et al. Real-time video counselling for smoking cessation. Cochrane Database Syst Rev 2019 Oct 29;2019(10):CD012659 [FREE Full text] [doi: 10.1002/14651858.CD012659.pub2] [Medline: $\underline{\text { 31684699] }}$

40. Roberts AL, Fisher A, Smith L, Heinrich M, Potts HWW. Digital health behaviour change interventions targeting physical activity and diet in cancer survivors: a systematic review and meta-analysis. J Cancer Surviv 2017 Dec 4;11(6):704-719 [FREE Full text] [doi: 10.1007/s11764-017-0632-1] [Medline: 28779220]

41. Schembre SM, Liao Y, Robertson MC, Dunton GF, Kerr J, Haffey ME, et al. Just-in-time feedback in diet and physical activity interventions: systematic review and practical design framework. J Med Internet Res 2018 Mar 22;20(3):e106 [FREE Full text] [doi: 10.2196/jmir.8701] [Medline: 29567638] 


\title{
Abbreviations
}

MET: metabolic equivalent of task

NHMRC: National Health and Medical Research Council

PRISMA: Preferred Reporting Items for Systematic Reviews and Meta-Analyses

RCT: randomized controlled trial

SMD: standardized mean difference

SNAP: smoking, nutrition, alcohol, physical activity

\author{
Edited by $G$ Eysenbach; submitted 14.08.20; peer-reviewed by T Webb, E James; comments to author 21.09.20; revised version \\ received 09.11.20; accepted 22.11.21; published 21.12 .21 \\ Please cite as: \\ Tzelepis F, Mitchell A, Wilson L, Byrnes E, Haschek A, Leigh L, Oldmeadow C \\ The Long-Term Effectiveness of Internet-Based Interventions on Multiple Health Risk Behaviors: Systematic Review and Robust \\ Variance Estimation Meta-analysis \\ J Med Internet Res 2021;23(12):e23513 \\ URL: https://www.jmir.org/2021/12/e23513 \\ doi: $10.2196 / 23513$ \\ PMID:
}

CFlora Tzelepis, Aimee Mitchell, Louise Wilson, Emma Byrnes, Alexandra Haschek, Lucy Leigh, Christopher Oldmeadow. Originally published in the Journal of Medical Internet Research (https://www.jmir.org), 21.12.2021. This is an open-access article distributed under the terms of the Creative Commons Attribution License (https://creativecommons.org/licenses/by/4.0/), which permits unrestricted use, distribution, and reproduction in any medium, provided the original work, first published in the Journal of Medical Internet Research, is properly cited. The complete bibliographic information, a link to the original publication on https://www.jmir.org/, as well as this copyright and license information must be included. 